annexed shall be entitled to registration under the said Act." Amongst the qualifications in Schedule A is that of "Licentiate of Apothecaries' Hall," and for this qualification Mr. Hallows was duly registered. "He was therefore, according to the letter and spirit of the law, a duly qualified medical practitioner, and call himself by what name he might, he was dniy protected by the 40th section, which makes it penal only for "falsely pretending" (by the use or employment of any of the terms therein set forth) that he is a duly registered person. Mir. Hallows was duly registered, and therefore it was utterly impossible for him to violate this section, because he could not so "pretend." It is a contradiction in terms, a monstrous absurdity, contrary to all reason and all logic, and I am confident that had he moved the Court of Queen's Bench for a writ of certiorari, to bring the conviction into that Court, it would have been instantly quashed. with costs. He did not avail himself of this, but, submitting to the expenses of the case, foiled his persecutor by becoming a member of the College of Surgeons.

Mr. Hallows is an entire stranger to me; $I$ never heard his name till brought before the public in this case; but I have now evidence that he is a highly respectable and honourable man, thongh not in a position to be oblivious of the expense to which he has been put in defending himself in this prosecution. I would therefore most earnestly solicit the sympathy of his medical bretliren in the tangible form of subscriptions to the amount of about fifty pounds, to corer his costs. I shall most cheerfully contribute one guinea, and hope some kind brother, more centrally situated than I am, will kindly undertake the treasurership, to whom I will instantly remit my subscriptiou such contributions to be published in THE LANCET, and the list to be open for one month.

I remain, Sir, yours very truly,

Ilfracombe, Devon, Kov. 25th, 1859. JOHX JONES.

\section{HEAT OF STOKE-HOLES.} To the Eaitor of The LANCET.

SIR,-An article appeared in The LAvCeT of Nov. 19th, relative to the excessive heat in stoke-holes. Now this is a matter with which I am well acquainted, having had extensive experience in it. In one sense, it is to be lamented that the scientific literature of the present day increases to so great and overpowering an extent, because it causes that which is now deemed old to be neglected, and thus enables the dishonest to palm off the old for the new; while, on the other hand, it allows a great deal of what is really valuable to fall into oblivion. I have not the "Philosophical Transactions" under my hand, but I may refer to a paper therein, which may be easily found, where there is a narrative of some experiments instituted by Dr. Birkbeck, and I think Sir Joseph Banks and others, to determine the amount of heat which can be conve. niently borne by the human frame. The temperature was something greatly above $130^{\circ} \mathrm{Fahr}$, which is so much complained of by the advertisers and humanity-mongers, and tended to show the admirable provision made by nature to maintain an uniform temperature in the body by means of perspiration and consequent evaporation from the surface.

Allow me now, Sir, to give you the result of my experience, extending over a period of nearly seven years. In large ocean steamers, the stoke-hole is situated at the bottom of the ship; it is capacions and kept clean; there is plenty of hatehway above tlirongh which the heated air ascends without opposition, and there is, consequently a return rush of fresh air, whether by an ample supply of windsails, or by the hatches themselves. There are always on watch two engineers (officers) on the platform, and a certain number of men : these latter consist of two classes, viz : firemen, whose duty it is to tend the furnaces, and coal-trimmers, who bring the coals to the stoke-hole, keep them properly trimmed, so as to preserve the trim of the ship, and remove the ashes at the termination of each watch. The temperature of the stoke-hole, within the tropics, is from $120^{\circ}$ to $130^{\circ} \mathrm{Fahr}$; but be it specially remarked, the air is perfectly dry, so that the perspiration evaporates with the greatest facility. The men, moreover, are clothed in flannel. The temperature increases as we ascend, as might be expected, for the windsails conduct the cooler and moister air into the stokehole. On board these ships there are as many seamen as there are firemen and trimmers, but there is more sickness among the seamen than among the others; and it is most prevalent of all with the waiters and other servants. Those in the stokehole are not more frequently taken ill on watch than are the sailors; and what does occur in such cases is that a man is brought up complaining of cramps, and then we may be sure he has been drinking copious dranghts of cold water without having oatmeal infused in it, with which, however, he is amply supplied, and which effectually preserves him from these cramus. I should have mentioned that the furnaces are furnished with double doors, having a current of air between them ; and I may add that often as I have tested the bodily temperature of men coming ont of the stoke-hole, $I$ have never found it to exceed what is natural-namely, 98 ${ }^{\circ} \mathrm{Fahr}$. As far as the Royal Mail Steam Packet Service is concerned, I am bound to say that, at whatever cost, nothing is omitted that may conduce to the well-being and comfort of all on board; and that my suggestions have always been listened to, and there is no doubt on my mind that were the apvariutus really necessary it would be had. The Government do well to wait and see if the Royal Mail Service adopt an alleged improvement, for the public is notoriously the worst served, and but too frequently made the rictim of jobs.

Allow me to add that the Odin does not belong to the Royal Mail Service, properly so called, where no such circumstance as that alluded to could by any possibility hape happened.

Loncion, Kov. 1859 I sm, Sir, yours faithfuily,

TATOR.

\section{CYSTIC DISEASE OF THE LIVER IN A FETUS. To the Editor of 'The LANCET.}

Sin,-I attended Mrs. B-_, aged twenty-seven, in her fourth accouchement on the 2 lst October. She previously had pains of a very severe character for three weeks. On making my first examination, I detected a vertex presentation. As the os was fully dilated, Iruptured the membranes, when a very large quantity of liquor amnii escaped. The head proceeded slowly to the os externum, which it passed with some difficulty; the shoulders were very slowly expelled. At this stage I was somewhat surprised that the abdomen did not follow so quickly as usual. I examined for the cause of the delay, and found a large tumour occupying the abdomen of the foetus. During its passage it distended the perinæum much more than the head, and required my serious attention for a few moments, but eventually passed without rupture. The child expelled, my first object was to obtain a view of the abnormal growth. I thought it was a plicenta implanted on the abdomen, it having very much the appearance of that body, the surface being covered with tortuous veins, and the umbilical cord inserted at its lower portion. I, however, found a placenta in utero. I dirided the cord and made a careful examination, and found it to be a cyst containing fluid, of the size of two clenched fists, extending from the ensiform cartilage to a little below the umbilicus; a line drawn from the nipple to the anterior superior spinons process of ilium on either side formed its boundaries laterally. The integuments and muscular structures of abdomen seemed to terminate by rounded edges at the circumference of the cyst, to which they were adherent. 'The child (a female) was remarkably well developed, but had cedema of face, neck, and scalp. She was born alive, but only lived ten rninutes. I consequently made an examination of the bodr. I divided the cyst vertically, when upwards of a pint of serum escaped. Its walls were very thick, of an azure tint. The liver was very large and congested, and the cyst was formed in the parenchyma of that organ; there was total absence of abdominal walls underneath it. All the other organs were healthy and wormal.

I am, Sir, your obedient servant.

Willingham, Nov. 1859. J. C. B. Suallmax, M.D.

\section{THE EVILS OF LITTLE HOSPITALS. To the Ealitor of THE LAXCET.}

Sre,-Much attention has justly been attracted to the numerous infringements upon the emoluments of legitimate medical practice, and measures, more or less effectual, are, from time to time, taken to mitigate the evil. We, notwithstanding, fondly cherish an intramural thief which preys upon us mercilessly.

I believe it may be stated, withont fear of contradiction, that the greatest enemy the general practitioner, and more especially the Poor-law medical officer, has to contend with, is the third-class hospitals of small towns. These institutions 